\title{
No Identifiable Line of Differentiation
}

National Cancer Institute

\section{Source}

National Cancer Institute. No Identifiable Line of Differentiation. NCI Thesaurus. Code C121813.

A laboratory finding indicating that the line of differentiation in a cellular infiltrate cannot be identified. 